\title{
ФУНКЦИОНАЛЬНО-СЕМАНТИЧЕСКИЕ ОСОБЕННОСТИ ИНФИНИТНОЙ ФОРМЫ ГЛАГОЛА «МАСДАР» В КАРАТИНСКОМ ЯЗЫКЕ
}

\section{FUNCTIONAL AND SEMANTIC FEATURES OF THE INFINITIVE FORM OF THE VERB "MASDAR» IN THE KARAT LANGUAGE}

\section{R. Pahrudinova \\ H. Dzhamaludinova F. Kazimagomedova}

Summary: The article conducted a study that showed the similarity and clearly expressed lexical and syntactic difference of Masdar from the verb name in the Karatin language. Masdar organically combines both verbal and nominal properties. The connection of the «Masdar» with the name in the Avar language is expressed, first of all, in the change of the «Masdar» in the cases according to the type II declension of nouns. The commonality with finite forms of the verb is manifested both in the root morpheme and in the categorical features of the verb such as grammar class, number, negation, causation, transitive-intransigence. Masdar distinguishes between ordinary and long-term forms. In contrast to the verb Masdar. the categories of grammatical time and mood are not characteristic, because it does not correlate the action with the moment of speech. In its form, Masdar does not differ from the verb name, but syntactically these forms are always different.

In the sentence, Masdars act as an expanded (complicated) object and can be expressed in separate words or phrases.

Keywords: karatin language, verb, the masdar, verbal noun, grammatical categories.
Пахрудинова Рашидат Омаровна

К.филол.н., дочент, Дагестанский государственный педагогический университет (г. Махачкала) rashidat-2014@yandex.ru

Джамалудинова Хадижат Гамзатовна К.филол.н., ассистент, Дагестанский государственный педагогический университет (2. Махачкала)

Казимагомедова Фаина Исламовна

К.филол.н., дочент, Дагестанский государственный педагогический университет (2. Махачкала)

Аннотация: В статье проведено исследование, показавшее сходство и четко выраженное лексическое и синтаксическое различие масдара от отглагольного имени в каратинском языке. В масдаре органически соединены как глагольные, так и именные свойства. Связь масдара с именем в каратинском языке выражается, прежде всего, в изменении масдара по падежам по II типу склонения имен существительных. Общность с финитными формами глагола проявляется как в корневой морфеме, так и в категориальных признаках глагола таких, как грамматический класс, число, отрицание, каузатив, переходность-непереходность. Масдар различает обычные и длительные формы. В отличие от глагола масдару не характерна категории грамматического времени и наклонения, так как он не соотносит действие с моментом речи. По своей форме масдар не отличается от отглагольного имени, но синтаксически эти формы всегда различны. В предложении масдары выступают в качестве развернутого (осложненного) объекта и могут быть выражены отдельными словами или словосочетаниями.

Ключевые слова: : каратинский язык, глагол, масдар, отглагольное имя, грамматические категории, склонение, структурные типы.

встречаются и в каратинском языке: -хе (звархе «яркость, красочность»); -ху (макьуху «сонливость»); -льер (тохлъер «упущение»).

В аффиксах -хе и -ху, на наш взгляд, следует отделить компонент -х- от еи и -у, поскольку это разнофункциональные и разноуровневые величины: -х здесь является деривационным аффиксом глагола. Посредством этого аффикса образуются глаголы от имен существительных, например: пири «молния» - пирххалъа «блеснуть», «вспыхивать» - пирххер «блеск», «вспыхивание»; пурххалъа «пузыриться» - пурххер «образование волдыря»; макьу «сон» - макьухалъа «клонить ко сну» - макьуххур «сонливость» и т.д. Этот же суффикс выделяет и Т. Е. Гудава среди других элементов, образующих глагольную основу, «точная функция которых надлежащим образом пока не установлена» $[3$, с. 8].

Т.Е. Гудава выявляет в глагольных основах аварскоязыке выделяют еще аффиксы: -хе, -ху, -лъер, которые
М. Абдуллаев и Я. Сулейманов [1, с. 178], в аварском

1и1алер «чтение» (ц1 и1алальа «читать»);

-ур - заругъур «холод» (заругъалъа «замерзнуть»);

- ан - гьаан «виденье» (гьаанлъа «видеть»). Серия: Гуманитарные науки №10 октябрь 2020 г. 
го и андийских языков «определенный ряд суффиксов, которые, не являясь ни детерминативными суффиксами, ни тематическими показателями, срослись с основами. Имеются в виду суффиксы -ль, -хх и др.» [3 с. 44]. На наш взгляд, суффикс -хx- является деривационным суффиксом глагола. Посредством этого суффикса, как было уже сказано, образуются глаголы от имен существительных.

Все глаголы на -н (т.е. с аффиксом инфинитива -лъа) имеют в качестве форманта масдара -ли: сугьан «уставание»- сугьанлъа «уставать»; вушан «победа»- вушанлъа «победить» и т.д.

Все глаголы на -ль (т.е. с аффиксом инфинитива -лъа) имеют в качестве форманта масдара - $p$. Как известно, аффиксу инфинитива -лъа предшествуют тематические гласные -u-, -a-, -e-, -у-, -о-, причем основная масса глаголов располагают в качестве тематической гласной, оформляющей основу инфинитива, -p. Все глаголы с тематическим гласным - в и инфинитиве имели, на наш взгляд, в качестве форманта масдара 0 (нуль звука), например: гирер «лежание» - гиралъа «лежать»; бекьер «пахота» - бекьалъа «пахать».

В масдаре органически соединены как глагольные, так и именные свойства. Общность с финитными формами глагола проявляется в корневой морфеме, в категориальных признаках глагола (грамматический класс (волан (1 гр. кл.), йелан (II гр.кл.), белан (III гр.кл.), числе (волан / йелан / белан (ед.ч.) и релан (мн.ч.)), отрицании (воланч1елъер (для I грам. кл.), йеланч1елъер (для II грам. кл.), беланч1елъер (для III грам.кл.), реланч1елъер (для мн.ч.); «не просыпание») и каузативе (волан - йелан - белан - релан. «пробуждение»), в переходности-непереходности (в непереходных масдарах выражен грамматический класс субъекта, переходных - грамматический класс объекта, например: Имйа вохьар дия к1абалъеч1е. «Отца приход (I гр. кл.) мне не понравился». Илйа йехьвар дия к1абальеч1е. «Матери приход (II кл.) мне не понравился». Телеграмма бехьвар дийа к1абалъеч1е. «Телеграммы приход (III кл.) мне не понравился». Ц1еради бахьвар дийа к1абальеч1е. «Гостей приход (мн.ч.) мне не понравился».

Имена действия тяготеют к субъекту действия, если образованы от непереходных глаголов (мак1елъильль хъар - «плач ребенка»), но ориентируются на объект действия, если образовались от переходных глаголов (тарбия бекке мак1е беонлъа «воспитание ребенка»).

В отличие от глагола масдару не характерна категория грамматического времени, так как масдар не может соотнести действие с моментом речи. Масдар представляет собой название процесса безотносительно ко времени его совершения. Не характерна масдару и категория наклонения. Отсутствие в масдаре категорий вре- мени и наклонения является единственным препятствием для включения масдара в систему глагола.

Связь масдара с именем в аварском языке выражается, прежде всего, в изменении масдара по падежам (склонении). Г.И. Мадиева отмечает, что: «масдар аналогично существительному обладает способностью изменяться по падежам, классам и числам» [6, с. 107]. Склоняется масдар по II типу склонения имен существительных, напр.: басан - бицин «рассказывание» (гл. басанлъа «рассказывать»):

Ном. басан

Эрг. басанильль

Род. басанор

Дат. басанлъийа

Лок.І басанийа

Лок. II басанихъ

Лок . III басанильль

В структуре масдара категория числа каратинского языка выражается префиксально в виде переменного классно-числового показателя 6-: вохьар (ед.ч.) - бахьвар (мн.ч.), вохъер (ед.ч.) -бахъер (мн.ч.) и т.д. По грамматическим классам масдар изменяется подобно глаголу.

«В большинстве случаев масдар не отличается по своей форме от отглагольного имени; так, вач1ин может означать как «приход», так и «прихождение», «процесс прихода»; -ц1али - «учение, учеба» и «чтение», «процесс чтения», или «процесс учения» и т.п. Тем не менее, синтаксически эти формы всегда различны» [2, с. 260].

Масдар не сочетается с определением. А отглагольное имя, как и любое другое имя не допускает постановку перед ним определения: Ц1акъаб ришанхъер (отглагольное имя) идйа диб «Хорошая работа есть у меня». Ден вушанхъар (масдар) ц1акъа беку «Хорошо, что я работал» (досл.. «я работание хорошо случилось»). Дуб рок1ар (отглагольное имя) кагал богьов «Твоя болезнь, да уйдет!». Мен бок1альер (масдар) дийа биач1е «Я не знал, что ты болен» (досл.. «Ты недомогание я не знал»).

Являются ли слова ц1алер «учение» и бибер «кричание» масдаром или отглагольным именем в приведенных выше примерах можно проверить постановкой определения перед ними, напр.: Ц1акъаб и1алер хазина идйа «Хорошее учение есть клад»; Мена дубда бибер жебда бешда, Муса!! «Ты свой крик оставь, Муса». Мы видим, что в данных примерах они являются отглагольными именами, а не масдарами.

Самостоятельно, без сочетающихся с ним слов, масдар не может выступить ни в функции дополнения, ни в функции подлежащего. Но масдарные словосочетания могут выступить в качестве развернутого (осложненного) объекта. Следует учесть что в каратинском языке, как 
и в других языках, члены простого предложения могут быть выражены как отдельными словами, так и целыми словосочетаниями.

Масдарные словосочетания могут быть двучленными или трехчленными, в зависимости от переходности или непереходности глагола.

Форма масдара непереходного глагола может образовать только двучленное словосочетание структурного типа «Имя в номинативе + непереходный масдар», где имя в номинативе выражает субъект действия, а непереходный масдар - глагольное действие, напр.: Дийа биач1е мен бок1алъер «Я не знал о твоем заболевании» (Досл. «Я не знал ты заболевание»). В данном предложении двучленное словосочетание непереходного масдара выступает в функции осложненного объекта. В самом словосочетании имя в номинативе является всегда субъектом действия, а масдар непереходного глагола - выразителем глагольного действия.

Масдар переходного глагола образует трехчленные словосочетания следующих структурных типов:

1. Имя в эргативе + имя в номинативе + переходный масдар»: Дийа анлъе мена (эрг.) хъоча(абс.) ц1алоб(м.). «Я слышал, что ты читал книгу» (Досл. «Я слышал тобою книга чтение»).

2. «Имя в дативе + имя в абсолютиве + переходный масдар»: Дийа биида дува (дат.) йаши (абс.) к1абалъер (масс.) «Я знаю, что ты любишь девушек» (Досл. «Я знаю, тебе девушки любовь).

3. «Имя в локативе + имя в абсолютиве + переходный масдар»: Дийа бич1ч1е дува(лок.) имйа гьаанльер(м.) «Я понял, что ты увидел отца» (Досл. «Я понял на тебе отец видение»).

Семантическая структура всех трех конструкций одинакова: «семантический субъект + семантический объект + процесс глагольного действия». Во всех этих примерах масдарные словосочетания выступают выразителями осложненного объекта, масдар в словосочетании согласуется с объектом в классе и числе. Субъект не имеет формально выраженной грамматический связи с другими членами словосочетания.

Масдар переходного глагола может образовать также двучленные словосочетания следующих структурных типов: 1) «Имя в эргативе + переходный масдар»; 2) «Имя в номинативе + переходный масдар». [8, с. 179], напр.: Ишйа зебул бишанхъалъа к1абач1е «Нам не нравится работать целый день» (Досл: «Нам целый день работание не нравится»). Имя в эргативе зебул (от существительного зебу «день») в составе словосочетания не имеет формально выраженной связи с масдаром. Иначе обстоит дело, когда имя существительное в составе масдарного словосочетания стоит в номинативе. В послед- нем случае грамматическая связь имени существительного с масдаром выражается в согласовании в классе и числе (если масдар образован от классного глагола), напр.: Вашалоч10 бакъоб гьач1е биц1и1и ч1амер «Ребятами не подходит жевание жвачки». Ц1акъа беку гъане бегьер, гьач1вар икки маквак1ас бак1ва «Хорошо, что взяли хлеб, а то бы мы проголодались» (Досл. «Хорошо случилось хлеб взятие, а то бы мы проголодались»). Масдарные словосочетания во всех этих примерах выполняют функцию осложненного объекта.

В ряде случаев переменный классный показатель глагола в отглагольном имени представлен лишь в форме множественного числа, например: торч1ч1анлъа «драться»- торч141ен «драка (процесс)» - рагъ «драка, война»; маквак1альа «проголодаться» - маквак1ар «голодание» - ракъи «голод»; бекьалъа «пахать» - бекьер «вспашка (процесс)» - рекьи «пахота»; гьерц1альа «погасить» - гьери 1ер «погащение» - рец1ел «месть»; беччанлъа «бродить»- беччен «брожение»- реччебо- «закваска»; бач1альа «выбирать» - бач1ар «выбирание» - рищи «выборы»; к1абалъалъа «любить, нравиться» - к1абалъер «желанье» - рокьи «любовь». Этот факт отмечен также Л.И. Жирковым: «Часто также начальный родовой признак, живой в глаголе, окаменевает в отглагольном имени, например: бокьизе «желать», любить» (с начальным родовым признаком, но рокьи «любовь» (с неизменным p-, очевидно, первоначально представленная как действие взаимное» 4, с.38-39]. В принципе это то же самое, что и масдар (имя действия).

«В каратинском языке зарегистрированы и такие корневые морфемы, которые встречаются и в именных и в глагольных образованиях. При этом процесс номинации происходит исключительно посредством деривационных аффиксов, а процесс вербализации - при помощи обычных словоизменительных аффиксов» [5, с. 32].

В действительности же в каратинском языке представлено значительное количество лексем, способных как номинализоваться, так и вербализоваться, напр.:

именная лексема глагольная лексема

рич1ар «смерть» - бич1ар - «умирание» - бич1альа «умирать»;

гурх1ел «жалость» - гурх1и «жалостливое состояние» гурх1алъа «сжалиться»;

ургъел «печаль, дума» - ургъелда «раздумье» - ургъалъа «думать, размышлять»;

лълъукъер «ранение» - лълъукъалъа «ранить» и др.

К разряду исключительных случаев относятся также лексема сусук 1 - «сито», например:

сусук1 «сито» - сусук1ур «просеивание»- сусук1алъа «(просеять)».

Масдар в каратинском языке различает обычные и 
длительные формы. Длительные формы обнаруживают следующие закономерности:

1. Формы, образованные с помощью суффикса -p имеют в качестве форманта масдара -е: uleхе-рехер - (гл.ц 1ехалъа «спрашивать», масдар обычного вида - и1ехер - бокъекъер - (гл. бокъалъа «резать», масдар обычного вида - бокъер). При образовании масдара длительного вида посредством форманта - $p$ - сохраняется принцип образования масдара - посредством суффикса -е.

2. Формы масдара длительного вида, образованные посредством суффикса длительности -лъа- имеют в качестве категориального форманта -p: кьвабкьвалъа (гл. кьвабалъа «вбить, убить», масдар обычного вида - кьвабер).

3. Формы масдара длительного вида, образованные посредством суффиксального комплекса -ар-, имеют в качестве категориального форманта -p: и1ари1ар (гл.ц1аралъа - «пить», масдар обычного вида - ц1арер).

4. В формах масдара длительного вида, образованных посредством суффиксального комплекса -ервыступает тот же формант - $p$, что и в соответствующих формах масдара обычного вида: цехерехер (гл. и еехалъа «спросить, спрашивать», масдар обычного вида - и1ехер.

5. Форма масдара длительного вида, образованная посредством суффикса -е, имеет в качестве категориального форманта показатель -р: к1анц1к1анц1ер «попрыгивание» - к1анц1ер «прыгание», гл. к1анц1алъа «прыгать».Таким образом, масдар длительного вида имеет только два категориальных суффикса: 1) -p- при образовании форм масдара длительного вида посредством суффиксов длительности - $p$ - и -е; 2) -ль- при всех остальных случаях.

Отрицательная форма масдара образуется двумя способами. При первом способе образования масдара отрицательной формы производящей основой служит деепричастие на -вха: бегьевха - босун «взяв», вохьавха - вач1ун «придя», гегьевха - гьабун «сделав». Второй компонент представляет собой комплекс -ч1елъер: бегьеч1ельер «невзятие», вольач1ельер - «неприход», гегьеч1елъер «неделание». Возможно, комплекс -ч1елъер имеет генетическую общность с отрицательной частицей гьач1е «нет, не».

При втором способе образования масдара отрицательной формы производящей формой служит отрицательная форма глагола прошедшего времени: бегьеч1е (гл. багьалъа «брать, взять»); бисанч1е «не нашел» (гл.бисанлъа «найти»), гегьеч1е «не сделал» (гл. гагьалъа «(с)делать»). Вторым компонентом служит суффикс -лъер: бегьеч1ельер «невзятие», бисанч1ельер «необнаружение», гегьеч1елъер «неделание». В первом случае образования отрицательной формы масдара элемент отрицания содержится в составе аффикса, во второй случае -в составе производящей основы. Хотя эти формы и являются синонимами, они имеют различные семантические оттенки и различаются сферой применения. Так, отрицательные формы масдара, образованные посредством комплекса -льер , применяются только в сфере будущего. Мена гьоб ришанхъер гегьич1елъер дийа биидоб бик1ва. «я знал, что ты не сделаешь эту работу» (Досл. «Ты эту работу неделание (буд. вр.) я знал»).

Формы масдара отрицания, образованные посредством суффикса -лъер, применяются в сфере прошедшего, так как они выражают завершенность. Напр.: Мена гьоб ришанхъер геч1елъер дийа биидоб бик1ва. «Я знал, что ты не сделал эту работу» (Досл. «Тобой эта работа неделание (прош. вр.) я знал»). Вашащул йилохар кагъат хъвареч1елъер дийа бич1ч1е. «Я понял, что сын не написал матери письмо» (Досл. «Сыном матери письмо ненаписание (пр. вр.) я понял»).

В масдарных формах каратинского языка не выражена категория грамматического времени. Но в отрицательных формах масдара проводится семантическое различие прошедшего и будущего настоящего времени. То есть имеются самостоятельные формы масдара для прошедшего и для будущего времени.

Понудительная форма масдара (каузатив) совпадает с основой инфинитива побудительного глагола, напр.: гьаар «показ» - гл. гьаальа «показать», гьерч1ч1ар «избавление» - гл. гьерч1ч1алъа «разбудить, освободить». Масдар проявляет полное сходство с другими членами глагольной системы по признакам структурно-семантическим и частичное сходство по признакам категориальным (в масдаре представлены все грамматические категории глагола, кроме времени и наклонения).

Таким образом, масдар проявляет сходство с именем, изменяясь по падежам. То есть масдар является гибридной формой, находящейся в смешанной глагольно-именной зоне. Но сочетание глагольных и именных свойств не является особенностью только масдарных форм, это общая черта всех инфинитных форм глагола. И причастия, и деепричастия, сохраняя глагольные свойства, приобретают еще именные (причастия - прилагательного, деепричастия -наречия). В каратинском языке в масдаре превалирует глагольное значение. Масдар в каратинском языке - это полноправная форма глагола, которая относится к системе инфинитных форм глагола.

Исходя из вышесказанного, масдар каратинского языка можно квалифицировать как начальную форму каратинского глагола. Масдар служит производящей основой для инфинитива: вохьар (м) «приход» - вохьалъа (инф.) «прийти», бегьер (м) «взятие» - багьальа - (инф.) 
«взять». Масдар в каратинском языке не совпадает с отглагольным именем. От одной и той же основы образуются масдары и отглагольные имена. Первые - посредством реляционных суффиксов, последние - по- средством деривационных суффиксов. В случае, когда формы масдара и отглагольных имен формально совпадают, они имеют четко выраженное лексическое и синтаксическое различие.

\section{ЛИТЕРАТУРА}

1. Абдуллаев М.А., Сулейманов и Я.Г. Аварский литературный язык. Махачкала: Дагучпедгиз. -1965. -261с. -На авар.яз.

2. Бокарев А.А. Синтаксис аварского языка. М.-Л., 1949. -277 с.

3. Гудава Т.Е. Сравнительный анализ глагольных основ в аварском и андийских языках. Махачкала. НИЯЛ Даг.ФАН СССР. 1959. -235 с.

4. Жирков Л.И. Грамматика аварского языка. М., 1924, XIV, -178 с.

5. Магомедбекова 3.М. Каратинский язык. Тбилиси: Мецниереба, 1971. -291 с.

6. Мадиева Г.И. Морфология аварского литературного языка. Махачкала, 1980. -160 с.

7. Маллаева 3. М. Глагол аварского языка. Махачкала, 2007. -397 с.

8. Саидова П.И., Гарунова К.И. К характеристике масдара и масдарных словосочетаний в аварском языке. // Отглагольные образования в Иберийско-кавказских языках. Черкесск, 1989. -С.178-181.

( Пахрудинова Рашидат Омаровна (rashidat-2014@yandex.ru), Джамалудинова Хадижат Гамзатовна, Казимагомедова Фаина Исламовна.

\section{Журнал «Современная наука: актуальные проблемы теории и практики»}

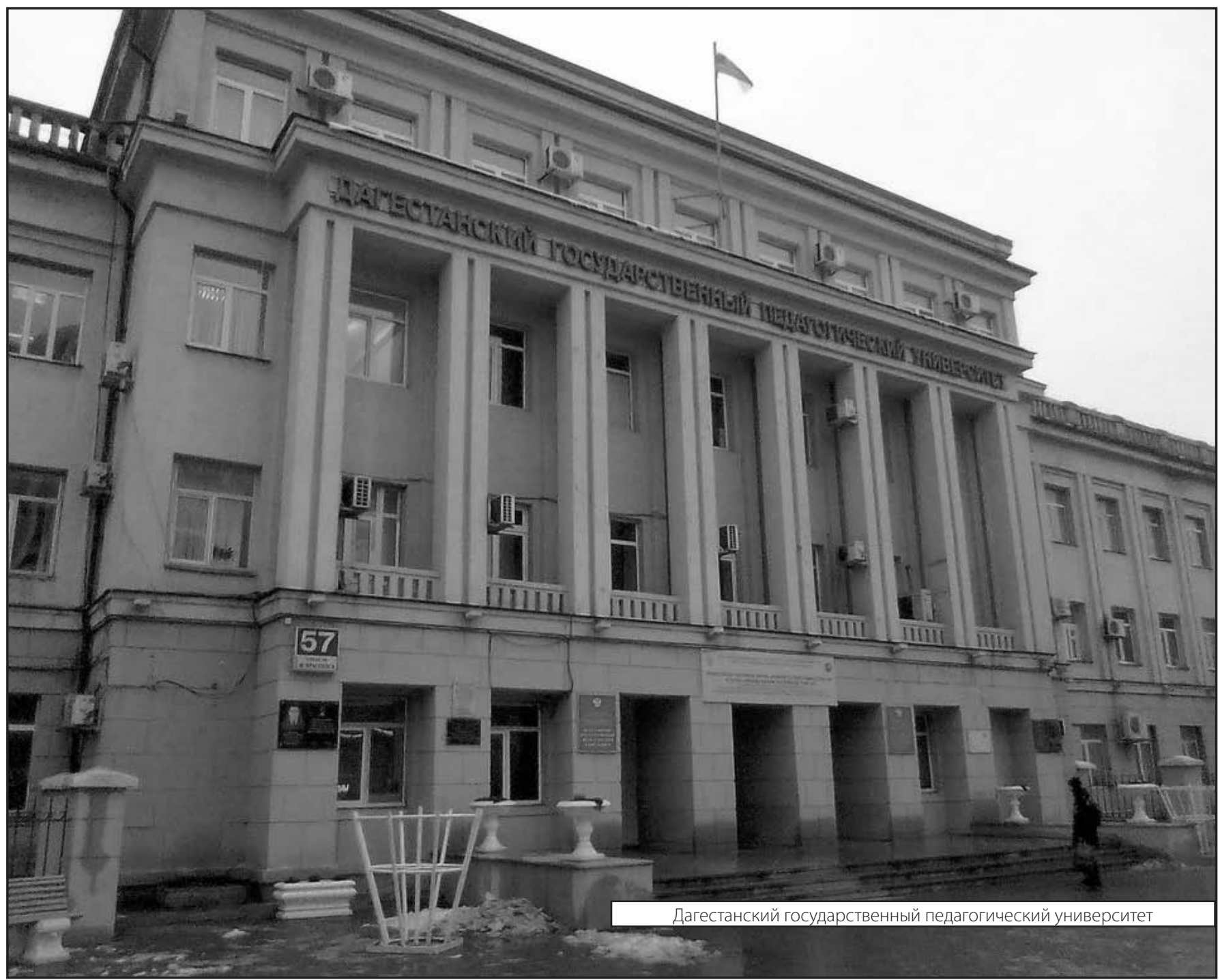

